\title{
DESLOCAMENTOS PENDULARES NA REGIÃO METROPOLITANA DE SÃO PAULO
}

CLÁudia ÂnTICo

\begin{abstract}
Resumo: O principal objetivo deste trabalho é analisar os deslocamentos pendulares ocorridos na Região Metropolitana de São Paulo como um indicativo de desigualdades e da heterogeneidade espacial e social existentes na região. A abordagem do tema foi feita em diferentes recortes espaciais para analisar os tipos de fluxos pendulares estabelecidos nos diversificados contextos sub-regionais. A principal fonte de dados utilizada foi o Censo Demográfico 2000.

Palavras-chave: Deslocamentos pendulares. População. Região Metropolitana de São Paulo.

Abstract: This study has aimed at analysing the commutings in the metropolitan area of São Paulo as an indication of inequalities and of social and spacial heteregoneity in the area. The theme has been approached in different spacial units to analyse the types of commutings established among the diversified subregional contexts. The main source of data used in this study was Demographic Census 2000.

Key words: Commutings. Population. Metropolitan Area of São Paulo.
\end{abstract}

$\mathrm{O}$ s dados do Censo Demográfico $2000^{1}$ revelaram que, no Brasil, 7,4 milhões de pessoas trabalhavam ou estudavam em municípios diferentes daqueles onde residiam. Esse tipo de deslocamento era realizado, principalmente, por residentes nos Estados de São Paulo e Rio de Janeiro, que registraram 29,2\% (2,1 milhões) e 13,2\% (980 mil), respectivamente, do total do país. A Região Metropolitana de São Paulo - RMSP concentrava $54,8 \%$ (1,1 milhão) dos que trabalhavam ou estudavam fora do município e residiam no Estado, e entre seus municípios, Osasco (116 mil), São Paulo (114 mil), Santo André (95 mil) e Guarulhos (94 mil) apresentaram os maiores contingentes, caracterizando, assim, esse deslocamento populacional como um fenômeno urbano concentrado em grandes cidades.

Entre os residentes na RMSP que trabalhavam ou estudavam fora do município de residência, $91 \%$ o faziam em municípios situados na própria RMSP, $6 \%$ em outras Unidades da Federação - UFs ou países e 3\% em outros municípios do interior do Estado de São Paulo, revelando o grande dinamismo interno metropolitano.

Os deslocamentos pendulares, caracterizados como um tipo de mobilidade populacional intra-urbana, mais intensos em áreas de maior concentração da população, tornaram-se um importante aspecto a ser considerado na dinâmica urbana metropolitana. Constituem uma dimensão da organização e da alocação das atividades econômicas, são mediatizados pela confluência dos processos de transformação do espaço urbano, e derivados, em grande parte, da sua forma de expansão e de ocupação pela população, além da distribuição das funções urbanas.

Desse modo, destaca-se a importância de seu estudo, especialmente em áreas metropolitanas, como a da Grande São Paulo, caracterizada tanto pela intensidade e riqueza 
de seu dinamismo econômico e populacional, como pelas fortes desigualdades sociais e heterogeneidade espacial. A RMSP concentra polaridades e processos contraditórios, apresenta diferentes faces em sua dinâmica intra-urbana e em sua configuração espacial, e é composta tanto pela multiplicidade e diversidade de territórios como pela complexidade de diferentes espaços.

Nesse sentido, o principal objetivo deste trabalho é analisar os deslocamentos pendulares ocorridos na RMSP nos anos 90, em espaços sub-regionais diversos existentes na metrópole. Quantificar e qualificar esses movimentos populacionais explicita grande parte das tendências de distribuição da atividade econômica e da localização da moradia no território dessa área metropolitana. Isso possibilita traçar suas relações com o processo de desenvolvimento metropolitano, que reproduz e se expande através de desigualdades sociais.
A principal fonte de dados utilizada para a análise dos fluxos pendulares da população pendular foi o Censo Demográfico 2000. Ressalte-se que os movimentos pendulares abordados no presente trabalho são os deslocamentos realizados pela população residente na RMSP entre o município de residência e o município de trabalho ou estudo.

Os dados selecionados foram explorados em diferentes recortes espaciais, envolvendo distintos tipos de agregações. Assim, em alguns momentos, os fenômenos foram analisados por meio de limites administrativos municipais, e, em outros, através da regionalização da RMSP em subregiões e vetores adotada pela Cia. do Metropolitano de São Paulo - Metrô, segundo critérios de acessibilidade. Nessa regionalização, o espaço metropolitano é dividido em seis sub-regiões, formadas por conjuntos de municípios do entorno metropolitano, e por nove vetores, formados pelo agrupamento de distritos do Município de São Paulo (Mapa 1).

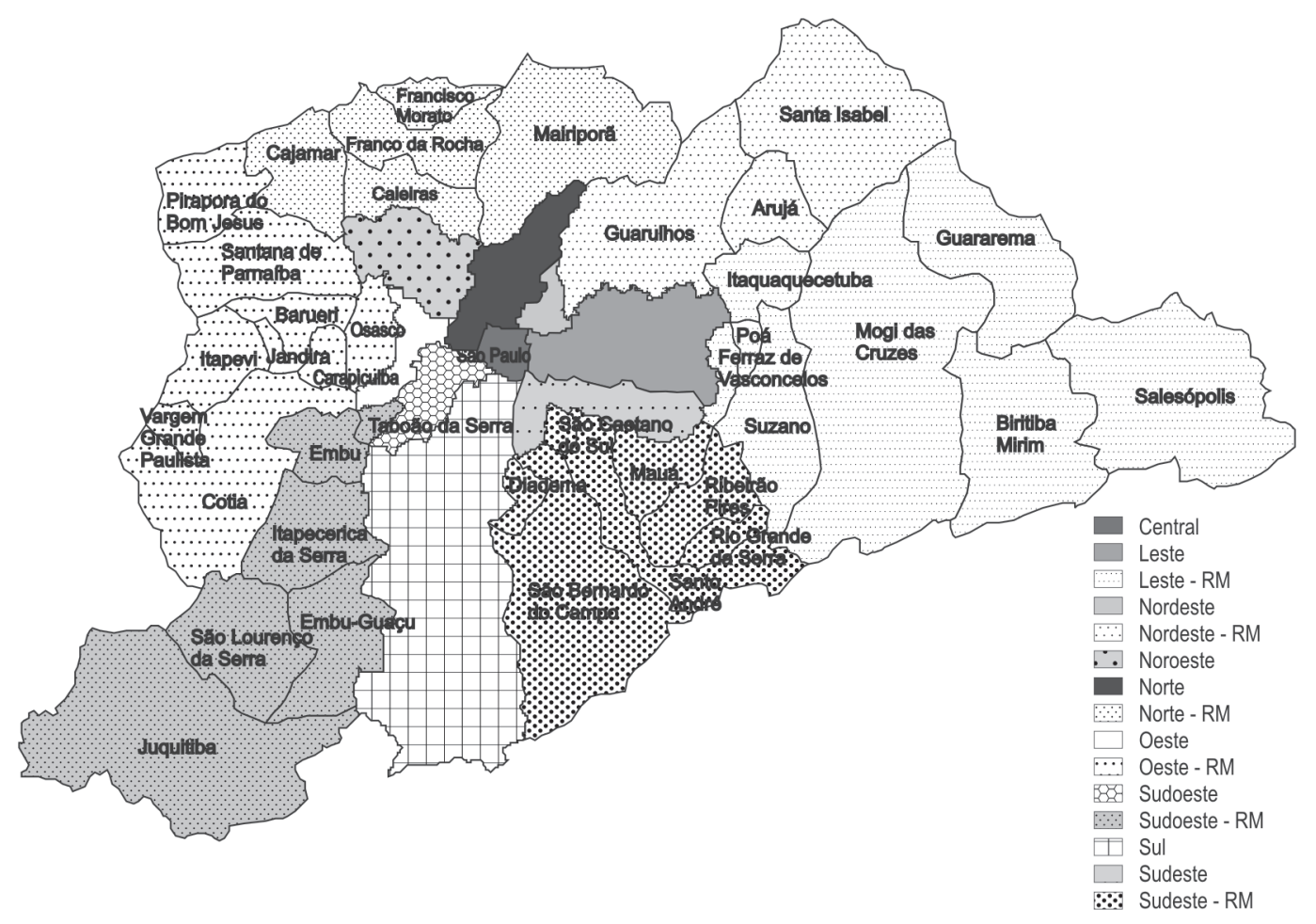

Fonte: Companhia do Metropolitano de São Paulo - Metrô. Pesquisa Origem-Destino 1997. 


\section{DESLOCAMENTOS PENDULARES E EXPANSÃO DA REGIÃO}

O espaço urbano contemporâneo está revestido por uma crescente complexidade e por múltiplos aspectos. É caracterizado por processos contraditórios e conflitos inerentes, marcado por transformações nas relações sociais e processos produtivos em escala mundial. A RMSP é marcada pela presença do contraste social e pela constituição de espaços fragmentados. Em partes específicas de seu território, ocorre o surgimento de áreas separadas, condomínios fechados, como Alphaville, Tamboré e Granja Viana, que podem ser considerados exemplos de suburbanização de altas e médias rendas na RMSP, assim como a expansão da população em condições bastante precárias de vida em áreas centrais e deterioradas do Município de São Paulo. Nesse espaço diferenciado e desigual, as maneiras como os grupos sociais resolvem a relação habitar-trabalhar, as estratégias utilizadas, tornam-se diferenciadas, atingindo-os de modo distinto.

Nesse contexto, os deslocamentos pendulares na RMSP relacionam-se a aspectos ligados à espacialização das atividades econômicas e dos locais de moradia, gerando a configuração de locais com funções distintas, permeados pelo acesso diferenciado à terra e pela divisão regional do trabalho metropolitano.

Logo, os movimentos pendulares estão relacionados a um processo mais amplo de ocupação, estruturação e expansão da RMSP. Nele, as questões relacionadas à moradia e ao emprego colocam-se como importantes dimensões de análise para o entendimento do papel e implicações desses deslocamentos diários no processo de configuração e estruturação da área metropolitana - como resultado, surgem dinamismos diferenciados. De um lado, estão as questões relativas à transformação das atividades econômicas da RMSP: redução do emprego industrial; crescimento e diversificação das atividades terciárias; tendência à desconcentração dos locais de trabalho; enfim, combinações de mudanças na forma de absorção da força de trabalho pelo mercado com precarização das relações de trabalho e elevados índices de desemprego. Do outro lado, podem ser citadas as questões relativas às modalidades de ocupação e parcelamento do solo, à especulação imobiliária, às políticas públicas, situadas num contexto de valorização de áreas centrais e da falta de alternativas habitacionais acessíveis para os grupos sociais em piores condições de vida. Nesse sentido, o deslocamento pendular, além de registrar a movimentação cotidiana no espaço metropolitano, é a evidência mais clara de como se constitui o mercado de trabalho na Região Metropolitana e a segmentação dos locais de moradia e de trabalho, que se estabelecem por lógicas distintas neste aglomerado urbano (MONTALI, 1991, p. 8).

Desde os anos 50, a forma de ocupação da RMSP através da expansão das periferias (BÓGUS; TASCHNER, 1986) - é indicativa de desigualdades internas nos processos de formação e transformação espaciais e urbanas. Esse fenômeno também pode ser constatado pelos níveis de crescimento populacional, que são mais elevados nos municípios que compõem o entorno metropolitano do que no município central, e também pelo movimento migratório intrametropolitano que segue na mesma direção. Tais processos, associados à concentração de empregos na área central, resultam no distanciamento crescente entre os locais de residência e de trabalho, e na necessidade de longos percursos diários a diferentes parcelas da população metropolitana.

Tais processos ainda podem ser observados com certa intensidade durante os anos 80 e 90, quando a configuração de espaços regionais se consolida, e estes são destacados como subcentros locais, em termos de sua importância na redistribuição populacional e da localização de empregos. O fortalecimento dessas áreas afeta os deslocamentos casa-trabalho da população residente na RMSP, intensificando a diversificação de movimentos e de grupos sociais envolvidos.

Em termos de expansão e absorção dos movimentos migratórios intrametropolitanos, a importância das áreas do entorno metropolitano no processo de redistribuição interna da população ${ }^{2}$ indica a relação existente entre os deslocamentos pendulares e a constituição espacial da RMSP.

A intensificação dessa mobilidade (intrametropolitana) certamente foi um dos condicionantes do surgimento elou crescimento das formas de movimentação populacional bastante típicas de regiões com grande nivel de integração, como é o caso da migração pendular. Esta não só reflete o distanciamento progressivo entre o lugar de moradia e o de trabalho, fruto da não-coincidência dos padrões de distribuição da população e da atividade econômica e social dentro da Região Metropolitana, mas também elementos ligados à forte segregação espacial da população (CUNHA, 1994, p. 122). ${ }^{3}$ 
No atual contexto de redistribuição espacial da população, marcado pela diversidade de deslocamentos populacionais, várias dimensões urbanas passam a ter um significativo papel na decisão de migrar, podendo-se considerar desde valores difundidos na sociedade em relação à busca de uma qualidade de vida melhor, até estratégias e arranjos ligados à proximidade e à acessibilidade ao local de trabalho, ou à possibilidade de aquisição de moradia, mesmo que em áreas mais afastadas do trabalho, evidenciando diferenças qualitativas entre grupos populacionais. Assim, os movimentos pendulares tornam-se uma dimensão importante a ser considerada tanto para a dinâmica urbana regional, como também para a decisão de migrar(BAENINGER, 2000).

\section{PRINCIPAIS DESLOCAMENTOS PENDULARES}

As distâncias diárias a serem percorridas, a acessibilidade e o tempo de deslocamento necessário para satisfazer as necessidades de trabalho e consumo podem influenciar diretamente a permanência da população na região - e isso vem ocorrendo no processo de redistribuição demográfica interna na RMSP desde a década de 80, com a incorporação de municípios mais distantes.

O Censo Demográfico 2000 registrou um total de 1.184.881 pessoas com o local de trabalho ou estudo diferente do município de residência na RMSP - o que representava $10,1 \%$ do total de trabalhadores/estudantes. Dentre os municípios que compõem a RMSP, pode-se destacar Osasco e o Município de São Paulo, com volumes de população pendular acima de 100 mil pessoas, além de Santo André, Guarulhos, São Bernardo do Campo, Carapicuíba, Mauá e Diadema, com volumes entre 50 e 100 mil pessoas (Tabela 1). Entretanto, observa-se que o impacto da proporção da população pendular é bastante diferenciado no conjunto de municípios: revelam-se especificidades relacionadas a cada um deles quanto a sua inserção na divisão social do trabalho metropolitano.

Entre os residentes na RMSP que trabalhavam ou estudavam fora do município de residência, 91\% o faziam em municípios situados na própria RMSP (1.074.407 pessoas). No contexto regional metropolitano, considerando apenas o montante de fluxos pendulares ocorridos entre os municípios da RMSP, verifica-se que o Município de São Paulo concentrou, em seu território, o maior número absoluto de deslocamentos. Em 2000, recebia 612.222 pessoas residentes em outros municípios da área metropolitana - cifra que significava $57 \%$ do total de movimentos pendulares de toda a região. Portanto, configurava-se como principal destino das pessoas que trabalhavam fora do município de residência (Tabela 2).

No sentido inverso a esse fluxo, ou seja, do Município de São Paulo em direção aos demais municípios da RMSP, a participação sobre o total de movimentos pendulares foi de $8,4 \%$ ( 90.157 pessoas).

Finalmente, excluindo o Município de São Paulo, os deslocamentos pendulares realizados entre municípios vizinhos pertencentes à mesma sub-região ("movimento pendular intra-regional") representavam 30,6\% (329.176 pessoas) do total de movimentos em 2000. E os fluxos registrados entre municípios pertencentes a diferentes sub-regiões (movimento pendular inter-regional) tiveram uma participação de 4\% (42.852 pessoas), como pode-se observar na Tabela 2. Os fluxos pendulares intra e interregionais são importantes para o entendimento da dinâmica dos movimentos pendulares da metrópole, uma vez que indicam a tendência de um potencial de crescimento desse fenômeno, pela configuração de novas trajetórias pendulares.

As pesquisas Origem-Destino, ${ }^{4}$ realizadas pela Companhia do Metropolitano de São Paulo - Metrô em suas edições de 1987 e 1997, indicaram, na evolução temporal dos fluxos numericamente mais significativos, a manutenção e o engrossamento de trajetórias pendulares já existentes em 1987 não apresentavam mudanças importantes no sentido dos movimentos pendulares ou dos tipos de deslocamentos, mas sim a continuação da tendência de concentração dos fluxos em direção ao Município de São Paulo. Entretanto, excluindo-se o Município de São Paulo, a crescente tendência de aumento da participação dos deslocamentos pendulares - ocorridos entre os municípios da RMSP tanto entre municípios vizinhos pertencentes à mesma sub-região como entre municípios pertencentes às diferentes subregiões - vem revelando a configuração e consolidação de sub-centros regionais.

Dentre os municípios mais dinâmicos no contexto da RMSP, pode-se observar a intensidade de deslocamentos pendulares provenientes de Osasco e Guarulhos em direção ao Município de São Paulo, além de fluxos ocorridos entre os municípios pertencentes às sub-regiões Sudo este (próximos a Osasco), Sudeste (ABC) e Leste (Itaquaquecetuba, Ferraz de Vasconcelos). A intensificação desses movimentos vem ocorrendo em áreas incorporadas pela expansão do crescimento metropolitano desde os anos 80 . 
TABELA 1

População, por Local de Trabalho ou Estudo, e Participação da População Pendular Região Metropolitana de São Paulo - 2000

\begin{tabular}{|c|c|c|c|c|}
\hline \multirow{2}{*}{$\begin{array}{l}\text { Municípios } \\
\text { de Residência }\end{array}$} & \multicolumn{3}{|c|}{ Local de Trabalho ou Estudo } & \multirow{2}{*}{$\begin{array}{c}\text { \% da População } \\
\text { Pendular }\end{array}$} \\
\hline & $\begin{array}{l}\text { No Município } \\
\text { de Residência }\end{array}$ & $\begin{array}{c}\text { Em Outro } \\
\text { Município ou País }\end{array}$ & Total & \\
\hline RMSP & 10.534 .403 & 1.184 .881 & 11.719 .284 & 10,11 \\
\hline Osasco & 312.148 & 116.763 & 428.911 & 27,22 \\
\hline São Paulo & 6.815 .854 & 114.414 & 6.930 .268 & 1,65 \\
\hline Santo André & 316.638 & 95.498 & 412.136 & 23,17 \\
\hline Guarulhos & 591.376 & 94.823 & 686.199 & 13,82 \\
\hline São Bernardo do Campo & 388.137 & 83.134 & 471.271 & 17,64 \\
\hline Carapicuíba & 143.256 & 72.603 & 215.859 & 33,63 \\
\hline Mauá & 164.574 & 62.551 & 227.125 & 27,54 \\
\hline Diadema & 180.715 & 51.720 & 232.435 & 22,25 \\
\hline Itaquaquecetuba & 120.963 & 44.713 & 165.676 & 26,99 \\
\hline Taboão da Serra & 89.130 & 43.711 & 132.841 & 32,90 \\
\hline Embu & 98.967 & 35.584 & 134.551 & 26,45 \\
\hline Ferraz de Vasconcelos & 58.661 & 28.800 & 87.461 & 32,93 \\
\hline São Caetano do Sul & 65.755 & 28.524 & 94.279 & 30,25 \\
\hline Itapevi & 71.055 & 28.507 & 99.562 & 28,63 \\
\hline Franscisco Morato & 53.206 & 28.140 & 81.346 & 34,59 \\
\hline Barueri & 114.723 & 24.501 & 139.224 & 17,60 \\
\hline Suzano & 118.953 & 23.750 & 142.703 & 16,64 \\
\hline Jandira & 40.058 & 20.791 & 60.849 & 34,17 \\
\hline Poá & 40.825 & 20.546 & 61.371 & 33,48 \\
\hline Itapecerica da Serra & 64.447 & 20.466 & 84.913 & 24,10 \\
\hline Mogi das Cruzes & 192.118 & 19.800 & 211.918 & 9,34 \\
\hline Franco da Rocha & 46.667 & 18.305 & 64.972 & 28,17 \\
\hline Ribeirão Pires & 48.706 & 17.847 & 66.553 & 26,82 \\
\hline Cotia & 83.720 & 17.303 & 101.023 & 17,13 \\
\hline Santana de Parnaíba & 35.510 & 13.617 & 49.127 & 27,72 \\
\hline Caieiras & 33.827 & 12.775 & 46.602 & 27,41 \\
\hline Arujá & 29.406 & 8.322 & 37.728 & 22,06 \\
\hline Rio Grande da Serra & 14.384 & 7.970 & 22.354 & 35,65 \\
\hline Mairiporã & 33.925 & 6.368 & 40.293 & 15,80 \\
\hline Embu-Guaçu & 29.290 & 5.084 & 36.125 & 14,07 \\
\hline Vargem Grande Paulista & 25.185 & 3.962 & 22.069 & 17,95 \\
\hline Cajamar & 13.141 & 3.356 & 32.646 & 10,28 \\
\hline Santa Isabel & 6.207 & 2.377 & 27.562 & 8,62 \\
\hline Biritiba Mirim & 13.141 & 1.986 & 15.127 & 13,13 \\
\hline Pirapora do Bom Jesus & 6.207 & 1.724 & 7.931 & 21,74 \\
\hline Guararema & 12.731 & 1.622 & 14.353 & 11,30 \\
\hline Juquitiba & 16.406 & 1.063 & 17.469 & 6,09 \\
\hline São Lourenço da Serra & 6.383 & 1.026 & 7.409 & 13,85 \\
\hline Salesópolis & 8.210 & 833 & 9.043 & 9,21 \\
\hline
\end{tabular}

Fonte: IBGE. Censo Demográfico 2000. 
TABELA 2

População Pendular, segundo Direção dos Fluxos para Trabalho ou Estudo

Região Metropolitana de São Paulo - 2000

\begin{tabular}{|c|c|c|}
\hline Direção dos Fluxos & $\mathrm{N}^{\text {os }}$ Absolutos & $\%$ \\
\hline Total & 1.074 .407 & 100,00 \\
\hline De Outros Municípios para São Paulo & 612.222 & 56,98 \\
\hline De São Paulo para Outros Municípios & 90.157 & 8,39 \\
\hline \multicolumn{3}{|l|}{ De Outros Municípios para } \\
\hline Outros Municípios (Intra-Regional) & 329.176 & 30,64 \\
\hline \multicolumn{3}{|l|}{ De Outros Municípios para } \\
\hline Outros Municípios (Inter-Regional) & 42.852 & 3,99 \\
\hline
\end{tabular}

\section{DESLOCAMENTOS PENDULARES NOS ESPAÇOS SUB-REGIONAIS}

Considerando os deslocamentos pendulares ocorridos nas seis sub-regiões já apresentadas (Mapa 1) em termos dos tipos de movimentos, verifica-se que estas podem ser agrupadas segundo características comuns à composição de seus fluxos.

Observou-se uma proporção variada e diferenciada da população que trabalhava ou estudava em municípios diferentes do de residência, resultando num impacto distinto para os que compunham cada sub-região. Os maiores destaques foram apresentados por alguns municípios situados em diferentes sub-regiões: Norte (Caieiras, Franco da Rocha e Francisco Morato), Sudoeste (Taboão da Serra, Embu e Itapecerica da Serra), Leste (Ferraz de Vasconcelos, Poá e Itaquaquecetuba), Oeste (Osasco, Carapicuíba, Jandira e Itapevi) e Sudeste (Diadema, Santo André, Mauá, Rio Grande da Serra), conforme a Tabela 1 .

Relacionando tais municípios à sua participação na divisão social do trabalho metropolitano, percebe-se que, certamente, fazem parte de fenômenos diferenciados. Municípios industrializados integrantes das sub-regiões $\mathrm{Su}-$ deste e Oeste apresentam posições distintas dos municípios dormitórios situados ao Norte e a Leste da RMSP.

De modo geral, os municípios situados nas sub-regiões Norte, Leste e Sudoeste, que combinam uma elevada proporção de população pendular com características de maior crescimento populacional e estruturas etárias mais jovens, estabelecem fluxos pendulares principalmente com o Município de São Paulo. Além disso, configuram-se como áreas pouco dinâmicas, com menores densidades de empregos - o que os caracteriza como áreas mais precárias.

A predominância da concentração do fluxo pendular em direção ao Município de São Paulo e as elevadas proporções dessa população em relação ao total daquela que estuda ou trabalha (Gráfico 1) são as principais características dos diferentes tipos de movimentos pendulares que envolvem as sub-regiões Norte, Sudoeste e Leste.

De maneira geral, os municípios que compõem a área do entorno metropolitano apresentam uma estrutura etária mais jovem do que aquela observada na capital. As subregiões Norte, Leste e Sudoeste destacam-se nesse sentido, conforme pode ser observado nas pirâmides etárias (Gráfico 2).

As informações sobre a densidade de empregos no território da RMSP entre os anos de 1987 e 1997, que foram obtidas pelas pesquisas Origem-Destino, indicaram baixas concentrações em direção às sub-regiões que apresentavam elevadas proporções de pendulares e estruturas etárias mais jovens. Foi verificada uma tendência ao adensamento de empregos, especialmente em áreas centrais e em direção ao vetor Sudoeste do Município de São Paulo. Além disso, a expansão da mancha de baixas densidades (entre 25 e 50 empregos/ha) mostrou-se bastante expressiva, tanto em direção às áreas dos vetores Sudeste, Leste e Sul mais próximas às zonas centrais do Município de São Paulo como rumo aos municípios de Osasco, Guarulhos e ABC. A expansão dos locais de empregos ocorre, ainda, de forma concentrada, nas áreas mais centrais, em sub-centros regionais e áreas adjacentes (Mapa 2).

Desse modo, as sub-regiões Oeste, Sudeste e Nordeste destacam-se como as áreas mais dinâmicas do contexto metropolitano, e por isso abrigam tais subcentros locais. As sub-regiões Oeste e Sudeste constituem áreas com elevado contingente populacional de pendulares, níveis de crescimento populacional menores, e estruturas etárias mais envelhecidas. Assim, caracterizam-se como sub-regiões mais dinâmicas, com fluxos pendulares intra-regionais mais intensos.

Os números absolutos mais significativos de pendulares da RMSP e a elevada participação do movimento pendular intra-regional (Gráfico 1) são as principais características dos movimentos ocorridos nas sub-regiões Sudeste e Oeste.

Como são divididas em diferentes sub-regiões, as pirâmides etárias são indicativas das desigualdades existentes entre os municípios que compõem a área do entorno metropolitano. 
GRÁFICO 1

População Pendular, por Sub-Regiões de Residência, segundo Direção dos Fluxos para Trabalho ou Estudo Região Metropolitana de São Paulo - 2000

Sub-Região Norte

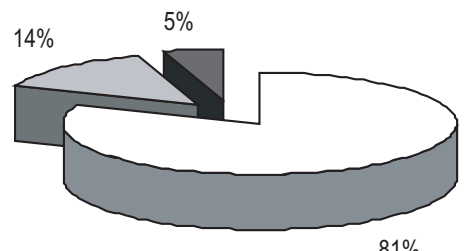

$81 \%$
Sub-Região Sudoeste

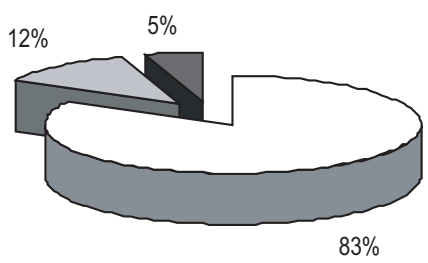

Sub-Região Oeste

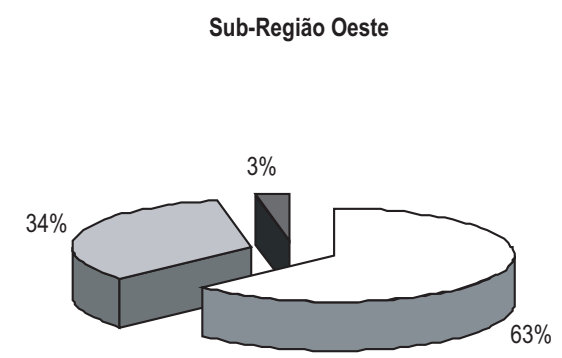

Sub-Região Leste

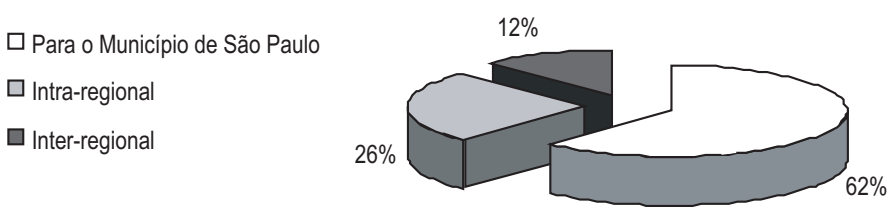

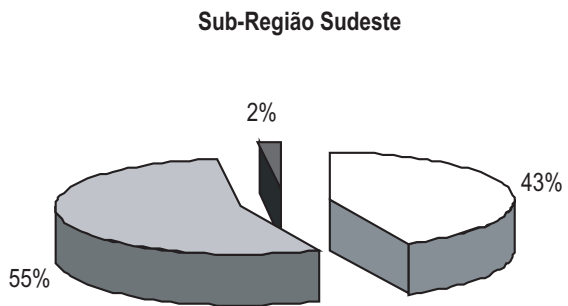

Fonte: IBGE. Demográfico 2000 (tabulações especiais - Nepo/Unicamp).

A sub-região Sudeste assemelha-se aos padrões etários do Município de São Paulo, registrando a base mais estreita da pirâmide e a maior proporção de idosos (Gráfico 2).

A sub-região Nordeste possui um dos fluxos pendulares numericamente mais importantes da RMSP, com concentração e predominância do deslocamento do município de Guarulhos em direção ao Município de São Paulo. Embora possua um ritmo de crescimento populacional bastante significativo e combinado a uma estrutura etária mais jovem, a sub-região Nordeste diferencia-se de outras que também têm essas características por apresentar um dinamismo econômico mais intenso e tendências de adensamento de emprego. Entretanto, mesmo configurando-se como um subcentro local, ela apresentou a menor participação do movimento intra-regional no total de seus deslocamentos pendulares, comparando-se com as demais subregiões da RMSP (Gráficos 1 e 2). 


\section{GRÁFICO 2}

Pirâmides Etárias, por Sub-Regiões de Residência, segundo Sexo

Região Metropolitana de São Paulo - 2000
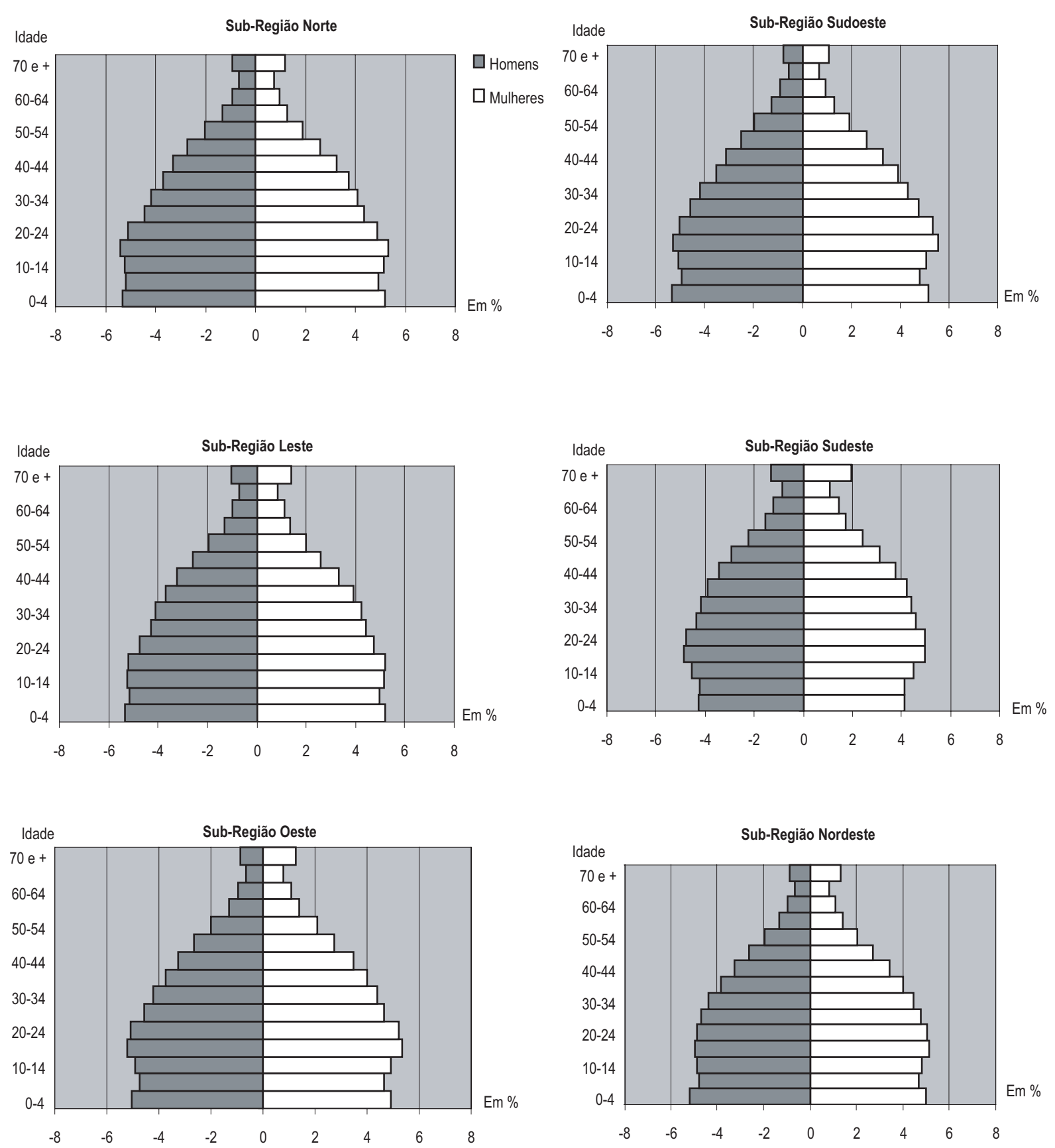

Fonte: IBGE. Censo Demográfico 2000 (tabulações especiais - Nepo/Unicamp). 
MAPA 2

Densidade de Empregos

Região Metropolitana de São Paulo - 1987-1997
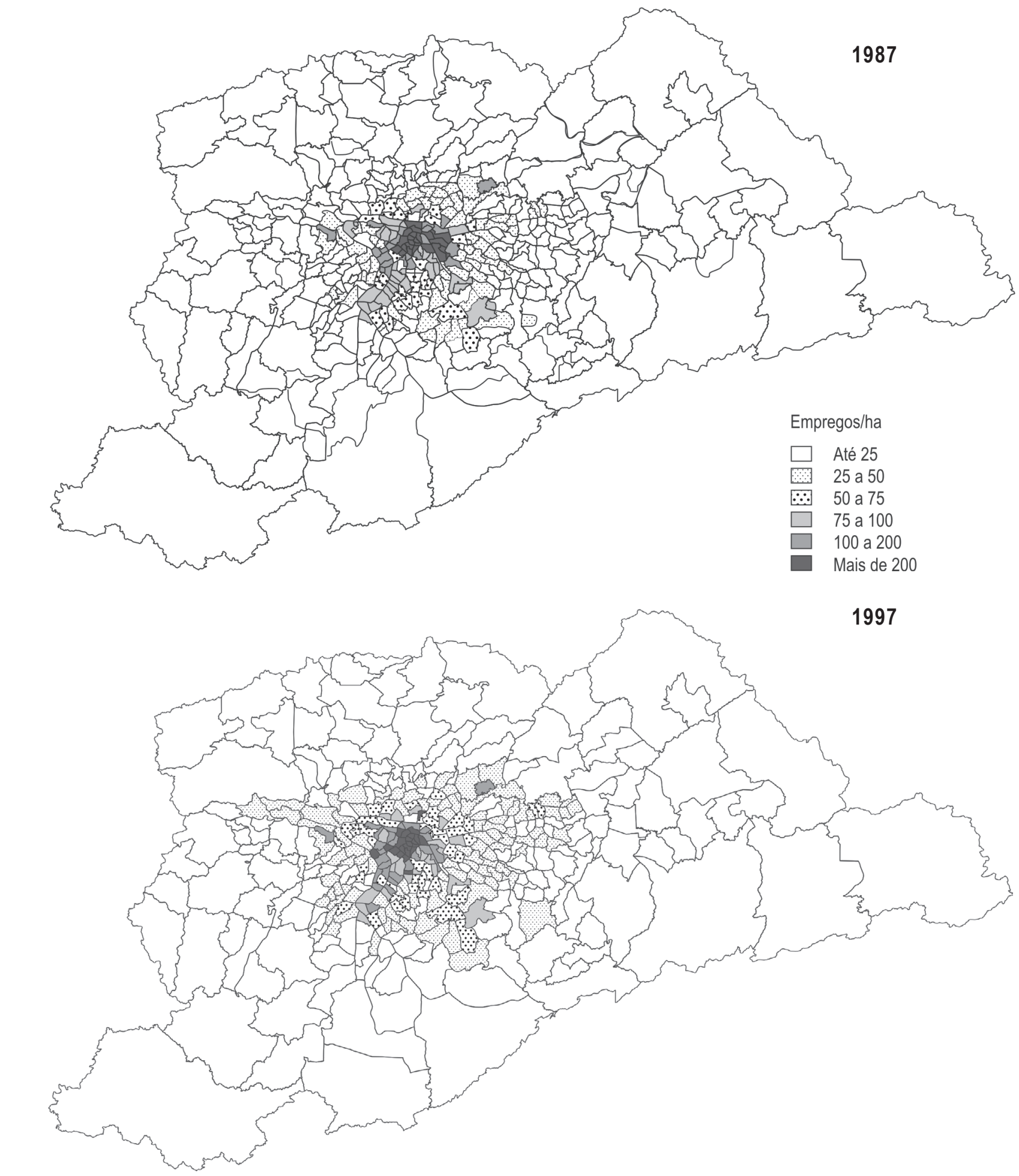

Fonte: Companhia do Metropolitano de São Paulo - Metrô. Pesquisa Origem-Destino 1987 e 1997. 


\section{CONSIDERAÇÕES FINAIS}

Realizada a partir dos dados do Censo Demográfico 2000 e das tendências trazidas pelas pesquisas Origem-Destino, a análise dos deslocamentos pendulares ocorridos nos municípios da Região Metropolitana de São Paulo - RMSP revelou importantes aspectos relacionados à configuração espacial metropolitana e sua heterogeneidade.

A maior concentração dos deslocamentos pendulares ocorridos no território da RMSP deu-se em direção ao Município de São Paulo. Juntamente com essa concentração de fluxos dirigidos à área central metropolitana e a menor intensidade dos movimentos em direção aos demais municípios, observou-se a tendência de aumento dos deslocamentos pendulares ocorridos entre os municípios da RMSP seja em suas dinâmicas intra-regionais ou inter-regionais.

Tal tendência revela a importância da dinâmica de configuração e consolidação de subcentros locais em algumas áreas na recepção dos trabalhadores pendulares de algumas sub-regiões, especialmente na Sudeste e Oeste, com destaque para os municípios de São Bernardo do Campo, Osasco e Barueri.

As sub-regiões Sudoeste, Oeste e Norte apresentaram as maiores proporções de população pendular: ou seja, elevado impacto sobre o total da população que trabalha e/ou estuda. De fato, tais sub-regiões caracterizam-se pela acentuada presença de municípios considerados como dormitórios no território metropolitano, como Taboão da Serra, Carapicuíba, Jandira e Francisco Morato. Entretanto, os tipos de fluxos observados nesses espaços sub-regionais são diferenciados; enquanto as sub-regiões Norte e Sudoeste apresentaram a predominância de fluxos pendulares dirigidos ao Município de São Paulo, a sub-região Oeste registrou um crescente dinamismo interno, ligado à diversificação da atividade econômica presente em seu território.

Por estarem situados em diferentes partes do território metropolitano, os municípios com elevado impacto de população pendular sobre o total populacional apresentam dinâmicas diferenciadas em seus fluxos pendulares, associadas aos processos de constituição e de expansão dos espaços sub-regionais.

Apesar de apresentar um pequeno impacto da população pendular sobre o total, a sub-região Nordeste registra o maior volume numérico de trabalhadores e estudantes pendulares da RMSP, em função do município de Guarulhos. Nessa sub-região, o dinamismo pendular interno é bastante reduzido, e os fluxos são quase que exclusiva- mente direcionados ao Município de São Paulo. Isso a diferencia de outras, como as sub-regiões Sudeste e Oeste, que também se caracterizam como antigas áreas de expansão derivadas da industrialização e adensamento metropolitano. Na sub-região Sudeste, mais da metade da população pendular trabalhava ou estudava em municípios da própria sub-região. Em menor medida, os movimentos pendulares intra-regionais também se destacaram na subregião Leste.

O que explica a maioria dos deslocamentos pendulares ocorridos na RMSP é tanto o processo de ocupação e expansão da metrópole (que está ligado ao crescimento das áreas do entorno metropolitano que abrigam grande parte da população sem condições de residir nas áreas mais centrais e valorizadas), como também a maior concentração de atividades produtivas em determinados espaços centrais - principalmente do Município de São Paulo. Assim, com o desenvolvimento de um padrão locacional de ofertas no mercado imobiliário em áreas mais afastadas e desvalorizadas, os trabalhadores pendulares utilizam como estratégia residir nos locais mais acessíveis, percorrendo maiores distâncias para chegar ao local de trabalho.

A distribuição espacial dos postos de trabalho mostra a acentuada concentração nas áreas centrais do Município de São Paulo. E mostra-se bastante incipiente, ainda que possa apresentar uma tendência à descentralização (indicada pelo crescimento e diversificação das atividades terciárias; com a instalação de grandes equipamentos de serviços em subcentros regionais; e com o surgimento de oportunidades de trabalho em novas áreas - fato que cria mais condições para que haja maior proximidade entre o local de moradia e o de trabalho e reduz a necessidade de longos trajetos).

Pode-se verificar que as regiões da cidade que se sobressaem pela grande concentração de empregos - vetores Sudoeste, Central e Oeste - destacam-se também pelas mais elevadas rendas médias familiares. Esse fato, relacionado à tendência de expansão da mancha urbana e da residência de trabalhadores de baixa renda em áreas periféricas, indica que é esse o grupo social mais penalizado por longos deslocamentos casa-trabalho.

Apesar de observar-se maior volume de deslocamentos pendulares da RMSP em direção ao Município de São Paulo, percebe-se que estes caminham para o fortalecimento das dinâmicas locais. Tais movimentos poderiam estar acompanhando um processo mais amplo de redistribuição interna da população, em que a migração intrametropolitana traz implicações decisivas. Já desde a década de 70, sua principal 
característica vem sendo a dispersão da população a partir do Município de São Paulo, além da significativa absorção de migrantes em alguns municípios do entorno metropolitano que vêm se configurando em subcentros regionais.

Entretanto, esse processo mostra-se ainda restrito e lento face ao dinamismo dos movimentos migratórios. Além disso, caracteriza a metrópole como um espaço extremamente heterogêneo e desigual, onde grande parcela da população precisa percorrer longos trajetos diários para chegar ao local de trabalho ou para satisfazer suas necessidades de consumo e lazer. Esse aspecto pode ser observado não só pelos deslocamentos intermunicipais, mas também pela grande movimentação intra-urbana interna aos municípios - principalmente no Município de São Paulo.

\section{NOTAS}

Esse trabalho está baseado na Tese de Doutorado em Demografia, intitulada Onde Morar e Onde Trabalhar: Espaço e Deslocamentos Pendulares na Região Metropolitana de São Paulo, defendida pela autora no Instituto de Filosofia e Ciências Humanas da Universidade Estadual de Campinas.

1. Resultados da Amostra - Migração e Deslocamento - divulgados em 2003.

2. Estudo sobre a migração intrametropolitana na RMSP na década de 70 (CUNHA, 1994) já apontava para a presença de áreas dinâmicas do entorno metropolitano na recepção dos fluxos migratórios provenientes do Município de São Paulo.

3. Atualmente, há um certo consenso entre os estudiosos do tema "população": eles acham que os "deslocamentos pendulares"não devem ser considerados "migração", pois os dois fenômenos configuram conceitos distintos. A "migração" envolve a mudança de residência e os "movimentos pendulares" têm como principal característica os deslocamentos entre diferentes municípios de residência e de trabalho (algumas definições também incluem município de estudo). Por ocasião da divulgação dos resultados da amostra do Censo Demográfico 2000, a Fundação IBGE denominou o fenômeno que envolve as pessoas que trabalham ou estudam fora do município de residência de "deslocamento".

4. A Pesquisa Origem-Destino, de caráter amostral, realizada tradicionalmente a cada dez anos desde 1967, coleta dados sobre as características socioeconômicas da população residente na RMSP e sobre a localização das atividades urbanas, com o objetivo de identificar os fatores que determinam o padrão das viagens, definido por suas origens, destinos, modos de transporte, motivos e horários. Uma nova edição da pesquisa foi realizada recentemente, com dados coletados em 2002, parcialmente divulgados.

\section{REFERÊNCIAS BIBLIOGRÁFICAS}

ÂNTICO, C. Deslocamentos pendulares nos espaços subregionais da Região Metropolitana de São Paulo. In: ENCONTRO NACIONAL DE ESTUDOS POPULACIONAIS, 14., Caxambu: Associação Brasileira de Estudos Populacionais Abep, 2004.

Onde morar e onde trabalhar: espaço e deslocamentos pendulares na Região Metropolitana de São Paulo. Tese (Doutorado) - IFCH/Unicamp, Campinas, 2003.
BAENINGER, R. Região, metrópole e interior: espaços ganhadores e espaços perdedores nas migrações recentes. Textos Nepo, 35. Campinas, Unicamp, 2000.

Deslocamentos populacionais, urbanização e regionalização. Revista Brasileira de Estudos de População. Brasília, Abep, v. 15, n. 2, jul./dez. 1998.

BÓGUS, L.M.M.; TASCHNER, S.P. Mobilidade espacial da população brasileira: aspectos e tendências. Revista Brasileira de Estudos de População, São Paulo, Abep, v. 3, n. 2, 1986.

BÓGUS, L.M.M.; VÉRAS, M.P.B. A reorganização metropolitana de São Paulo: espaços sociais no contexto da globalização. Cadernos Metrópole Desigualdade e Governança, São Paulo, Educ, n. 3, 1999.

CIA. DO METROPOlitANO DE SÃO PAUlo. Pesquisa Origem-Destino 1997. São Paulo: Secretaria de Transportes Metropolitanos, 1998.

Sintese das informações. Pesquisa Origem-Destino 1997. São Paulo: Secretaria de Transportes Metropolitanos, 1998.

Pesquisa Origem-Destino 1987. São Paulo: Secretaria de Transportes Metropolitanos, 1988.

CUNHA, J.M.P. Mobilidade populacional e expansão urbana: o caso da Região Metropolitana de São Paulo. 1994. Tese (Doutorado) - Instituto de Filosofia e Ciências Humanas, Universidade Estadual de Campinas, Campinas, 1994.

FONSECA, R.B. (Coord.). Impactos urbanos e socioeconômicos dos investimentos em transporte na Região Metropolitana de São Paulo. Campinas: Universidade Estadual de Campinas/ Núcleo de Economia Social, Urbana, Regional (Unicamp/Nesur), Convênio Metrô-Fecamp, 1999. (Projeto de Pesquisa).

IBGE. Censo Demográfico 2000. Rio de Janeiro.

GOTTDIENER, M. A produção social do espaço urbano. São Paulo: Edusp, 1993.

LANGENBUCH, J.R. A estruturação da Grande São Paulo, estudo de geografia urbana. Rio de Janeiro: IBGE, 1971.

MEYER, R.M.P. Atributos da metrópole moderna. São Paulo em Perspectiva, São Paulo, Fundação Seade, v. 14, n. 4, p. 3-9, out./dez. 2000.

MONTALI, L. Região Metropolitana de São Paulo: expansão e heterogeneidade. In: ENCONTRO NACIONAL DA ANPUR, 4., 1991 .

PATARRA, N.L. et al. (Org.). Dinâmica demográfica recente e a configuração de novas questões populacionais. In: Dinâmica demográfica regional e as novas questões populacionais no Brasil. Campinas: Unicamp, 2000.

VÉRAS, M.P.B. Novos olhares sobre São Paulo: notas introdutórias sobre territórios, espaços e sujeitos da cidade mundial. Revista Margem: Revisitando o Brasil, São Paulo, Educ, 1997.

VILLAÇA, F. Espaço intra-urbano no Brasil. São Paulo: Studio Nobel: Fapesp: Lincoln Institute, 2001.

Cláudia ÂnTico: Doutora em Demografia, Consultora na Fundap (SPBrasil).

Artigo recebido em 25 de abril de 2005 .

Aprovado em 22 de maio de 2005 